\title{
Investigations on Amphoteric Chitosan/TiO Bionanocomposites for Application in Visible Light Induced Photocatalytic Degradation
}

\author{
M. Bahal, ${ }^{1}$ N. Kaur, ${ }^{2}$ Nidhi Sharotri, ${ }^{1}$ and Dhiraj Sud $\mathbb{D}^{1}$ \\ ${ }^{1}$ Department of Chemistry, Sant Longowal Institute of Engineering and Technology (Deemed University), \\ Longowal 148106, Sangrur, Punjab, India \\ ${ }^{2}$ Department of Chemical Technology, Sant Longowal Institute of Engineering and Technology (Deemed University), \\ Longowal 148106, Sangrur, Punjab, India
}

Correspondence should be addressed to Dhiraj Sud; suddhiraj@yahoo.com

Received 14 October 2018; Revised 3 April 2019; Accepted 19 May 2019; Published 17 July 2019

Academic Editor: Camino Giovanni

Copyright (C) 2019 M. Bahal et al. This is an open access article distributed under the Creative Commons Attribution License, which permits unrestricted use, distribution, and reproduction in any medium, provided the original work is properly cited.

\begin{abstract}
The present investigation reports the greener synthesis and characterization of novel acrylic acid grafted amphoteric chitosan/TiO ${ }_{2}$ (CAT) bionanocomposites using ultrasonic radiations. This was done by grafting of acrylic acid onto chitosan in the presence of potassium persulfate by free radical polymerization reaction. The uniform distribution of metal oxide in $\mathrm{CA} / \mathrm{TiO} 2$ nanocomposites was achieved on grafted acrylic acid/chitosan which contains a weak anionic group (-COOH) using ultrasonication technique. Physiochemical techniques such as X-ray diffraction (XRD), field emission scanning electron microscope (FE-SEM), Fourier Transform Infra-Red spectroscopy (FT-IR), Energy Dispersive X-ray spectroscopy (EDX), and Thermal Gravimetric Analysis (TGA) were employed to characterize synthesized CAT. Nanocomposite CAT was applied for degradation of industrial dye. Malachite green (MG) often presents in the waste waters. The degradation kinetics were studied by monitoring the photocatalytic reaction for degradation of MG under visible light, and the rate constant of the reaction was found to be $7.13 \times 10^{-3} \mathrm{~min}^{-1}$. The current research work opens vistas for the new dimensions in the area of water treatment by solving the issues related to degradation reaction efficiency in visible light and cost effectiveness.
\end{abstract}

\section{Introduction}

The synergy between organic and inorganic materials offers the potential for the development of new generation innovative organic-inorganic composites with diversified applications in various areas such as catalysis, photo catalysis, separation technology, energy storage, and drug delivery [1-3]. The inorganic materials impart increased mechanical strength and thermal and chemical stability while retaining the flexibility of organic component. The hybrid materials show better electrical, chemical, or biochemical properties along with improvement in selectivity. Inorganic materials such as metal/metal oxide particles- $\mathrm{Al}_{2} \mathrm{O}_{3}, \mathrm{Fe}_{3} \mathrm{O}_{4}, \mathrm{ZrO}_{2}$, $\mathrm{TiO}_{2}$, carbon-based nanomaterials, zeolites, and silica [4-7] in nanocomposites can create symbiosis or multifunctional effects. The formation of nanocomposites by incorporating metal/metal oxide/metal sulphide nanoparticles into the polymeric materials has been emerged as focus area of research.

Chitin is the second most abundant polysaccharide after cellulose that consists of $\beta$-(1-4)-2-acetamido-2-deoxy-dglucose units. Polyaminosaccharide chitosan, a copolymer of 2-amino-2-deoxy-D-glucopyranose and 2-acetamido-2deoxy-D-glucopyranose units having $\beta$ (1-4) [8] linkages, is obtained by the deacetylation of chitin. Chitosan in an acidic solution behaves as cationic polyelectrolyte and forms complexes with a large number of negatively charged species such as proteins, anionic polymers, and drugs.

Nanocomposites are materials which consist of two components, with one of them having dimensions in nanometers $\left(10^{-9} \mathrm{~m}\right)$ range. Organic-inorganic nanocomposite materials are not the simple physical mixtures, but intimately linked via 
weak interactions/bond or strong interactions/covalent bond. These interactions have a profound effect on the material properties, in particular at the interface interaction, as well as on inner interfaces. $\mathrm{TiO}_{2}$ semiconductor is a well-known photocatalyst in the research field of energy and environment because of its unique properties like high efficiency, low cost, chemical and physical stability, noncorrosive nature, and widespread availability [9-11].

The band gap of $\mathrm{TiO}_{2}$ is $3.2 \mathrm{eV}$ for anatase and $3.0 \mathrm{eV}$ for rutile phase and requires more energy for photo excitation which is feasible only by absorption of photons of UV region. Thus, $\mathrm{TiO}_{2}$ can utilize only $5 \%$ of the entire solar spectrum, which led to its restricted application in the area of solar photocatalysis. Three fundamental approaches adopted to enhance photocatalytic activity in the visible region are (i) extension of excitation wavelength, (ii) band gap tuning, and (iii) extending charge-carrier recombination time. The different routes to achieve these parameters involve (1) surface chemical modification, (2) doping of photocatalyst (metal or nonmetal doping), and (3) coupling of semiconductor systems [12-18].

The detailed literature study reveals the chitosanpolyacrylic acid materials were prepared using microwave, high temperature, or radiations induced synthesis, and their applications as super adsorbent, for removal of cations, for controlled release of drugs, and as magnetic nanospheres have been explored [19-22]. The polymer based nanocomposites such as poly(vinyl alcohol)/polyacrylic $\mathrm{acid} / \mathrm{TiO}_{2} /$ graphene oxide have been used for photocatalytic degradation of pollutants [23]. Poly(vinyl alcohol)/ poly(acrylic acid)/carboxyl-functionalized graphene oxide nanocomposite membranes were prepared using electrospinning technique and modified with $\mathrm{TiO}_{2}$ nanoparticles. Their photocatalytic activity towards dye degradation and regeneration tendency was investigated [24]. Surface imprinted chitosan-TiO2 composites (SICT) was prepared using methyl orange as template [25]. Recently, aerochitintitania $\left(\mathrm{TiO}_{2}\right)$ composite was synthesized, which shows excellent adsorptive and photocatalytic activity for degradation of the model organic pollutant, methylene blue (MB) dye, under UV irradiation [26].

To the best of our knowledge, no reports on the greener synthesis and application of chitosan/polyacrylic acid/ $\mathrm{TiO}_{2}$ bionanocomposites in the area of visible light induced photocatalysis appeared in the literature. The aim of the present investigation is to assess the influence of modified amphoteric biopolymer chitosan on the performance of $\mathrm{TiO}_{2}$ photocatalyst, particularly in visible region. The present paper reports the greener synthesis of amphoteric chitosan/acrylic-TiO2 bionanocomposites using environmentally friendly ultrasound waves and their performance in white light induced photocatalytic degradation of industrial dye, malachite green.

\section{Material and Methods}

2.1. Chemicals. The following chemicals of analytical grade were used for synthesis of grafted CA/CAT bionanocomposite and photodegradation studies. Chitosan and acrylic acid used were purchased from Himedia, Loba Chemie. Malachite green was obtained from the Merck. Millipore water was used for preparing various solutions.

2.2. Ultrasonic Assisted Synthesis of Grafted Chitosan/TiO Bionanocomposites. Chitosan-acrylic acid biopolymer was synthesized by dissolving $0.5 \mathrm{~g}$ of chitosan in $10 \mathrm{ml}$ acetic acid (3\%) and left overnight for complete dissolution. The $15 \mathrm{ml}$ of monomer acrylic acid $(5 \mathrm{~mol} / \mathrm{L})$ was added dropwise to the viscous chitosan solution, followed by addition of $10 \mathrm{ml}$ of initiator potassium persulfate $(0.25 \mathrm{~mol} / \mathrm{L})$ with continuous stirring. The reaction mixture was subjected to ultrasonic waves at $40 \mathrm{KHz}$ in an ultrasonic bath for $30 \mathrm{~min}$, till thick white solution was obtained. The product was transferred to the Petri dish and dried in oven for 3 days at $60^{\circ} \mathrm{C}$. The gel formed was subsequently washed twice with lukewarm water to remove the monomer left and was confirmed by the $\mathrm{pH}$ measurements. The optimized conditions for better yield of the product was obtained by performing the polymerization reaction by varying the amount of monomer $(10,20,30,40$ $\mathrm{ml}$ ), amount of potassium persulfate $(12,14,16 \mathrm{ml})$, and time period for the exposure of ultrasonic waves $(15,20,30,45$ mins).

$\mathrm{TiO}_{2}$ nanoparticles were prepared by dissolving 8.52 gm of titanium isopropoxide in $20 \mathrm{~mL}$ ethanol followed by addition of $10 \% \mathrm{NH}_{4} \mathrm{OH}$ with continuous stirring till complete precipitation occurred. The reaction mixture after half an hour vigorous stirring was subjected to sonication in ultrasonic bath for 40 minutes, further followed by stirring for an hour, and kept overnight. The yellow colored precipitates obtained were purified by washing with methanol and filtered. The resultant product was dried in an oven at $100^{\circ} \mathrm{C}$ for 2 hours and calcinated at $450^{\circ} \mathrm{C}$ [17].

In order to obtain the chitosan-acrylic acid based nanocomposites, $100 \mathrm{mg}$ of $\mathrm{TiO}_{2}$ nanoparticles was dissolved to make suspension in iso-butyl alcohol, followed by ultrasonication for $1 \mathrm{hr}$ to attain well dispersed solution. The resultant nanoparticles solution was added to the polymerization reaction mixture of chitosan-acrylic acid prepared under optimized reaction conditions as discussed in proceeding section, followed by continuous stirring for $2 \mathrm{hrs}$ on magnetic stirrer. The reaction was proceeded further for 30 mins under ultrasonic waves, and the product obtained was transferred to the Petri dish and dried in oven for 3 days at $60^{\circ} \mathrm{C}$.

2.3. Instruments Used for CAT Nanocomposite Characterization and Photocatalytic Studies. X'Pert Pro was used for obtaining XRD graph of CAT. It is equipped with X'Celerator solid-state detector, using $\mathrm{Cu}-\mathrm{K} \alpha$ radiation $(\lambda=0.15418$ $\mathrm{nm})$. The sample was analyzed over $2 \Theta$ collection range 20-800. The accelerating voltage of $40 \mathrm{kv}$, emission current of 30 milliampere, and the scanning speed of 4.4 counts per second were used. FE-SEM (Carl Zeiss, Merlin compact model) at an accelerating voltage of $20 \mathrm{kV}$ was used to obtain microscopic feature of nanocomposite coated on gold. FT-IR spectra were recorded on Bruker FT-IR spectrophotometer. UV-VIS spectrometer (Shimadzu UV1800) was used for studying the photocatalytic degradation 
of malachite green. Thermal analysis up to $8000^{\circ} \mathrm{C}$ was done with the Shimadzu TGA-50 instrument. The photochemical experiments were performed in specially designed photocatalytic reactor equipped with white light source. An ultrasonicator of Labman Scientific instruments Pvt. Ltd. having a frequency of $40 \mathrm{KHz}$ was used to impose sound waves for the synthesis of uniformly distributed metal oxide photocatalysts.

\subsection{Photocatalytic Degradation Studies}

2.4.1. Photocatalytic Degradation of Malachite Green Using CAT. A specially designed double walled reaction vessel (volume $250 \mathrm{ml}$ ) was manufactured to evaluate the photocatalytic activity. The reactor was outfitted with white LED bulbs. The photocatalytic degradation studies were conducted on synthetic dye, malachite green, and organophosphate pesticide, quinalphos. To $100 \mathrm{ml}$ of $10 \mathrm{ppm}$ malachite green, $100 \mathrm{mg}$ of CAT was added and the resulting solution was kept for $30 \mathrm{~min}$ in dark. The absorbance was recorded. The solution was exposed to the white light $(15 \mathrm{~W})$. The rate of degradation was studied by monitoring the changes in the UV-Vis absorption at $\lambda$ max 617 $\mathrm{nm}$. Degradation efficiency (\%) has been calculated as follows.

$$
\text { Efficiency }(\%)=\frac{\left(C_{0}-C_{t}\right)}{C_{t}} \times 100
$$

\section{Result and Discussion}

Chitosan-acrylic acid/ $\mathrm{TiO}_{2}$ bionanocomposite was synthesized using greener ultrasonication technique and the optimized conditions for better percentage yield of the product obtained were found to be $15 \mathrm{ml}$ acrylic acid, $10 \mathrm{ml} \mathrm{K}_{2} \mathrm{~S}_{2} \mathrm{O}_{8}$, and reaction time $30 \mathrm{~min}$. Further, the polymerization reaction was carried out under optimized conditions to obtain bionanocomposite CAT. Acrylic acid monomer was anchored at the chitosan backbone in the presence of potassium persulfate as initiator. The free radical mechanism proposed for synthesis of chitosan-acrylic acid is in accordance with the earlier one reported for radical polymerization [27]. The proposed mechanism for synthesis of CAT is as follows.

Step 1. The first step in the polymerization reaction involves the generation of the free radicals $\mathrm{SO}^{\circ-}, \mathrm{HO}^{\circ}$.

Generation of Free Radical $\left(\mathrm{SO}_{4}{ }^{*-}, \mathrm{HO}^{*}\right)$

$$
\begin{aligned}
\mathrm{K}_{2} \mathrm{~S}_{\mathrm{s}} \mathrm{O}_{8} \text { sonication } & \longrightarrow 2 \mathrm{~K}^{+}+\mathrm{S}_{2} \mathrm{O}_{8}{ }^{2-} \\
\mathrm{S}_{2} \mathrm{O}_{8}{ }^{2-} & \longrightarrow 2 \mathrm{SO}_{4}{ }^{*-} \\
2 \mathrm{SO}_{4}{ }^{*-}+\mathrm{H}_{2} \mathrm{O} & \longrightarrow \mathrm{SO}_{4}{ }^{2-}+\mathrm{HO}^{*}+\mathrm{H}^{+} \\
\mathrm{SO}_{4}{ }^{*-}+\mathrm{HO}^{-} & \longrightarrow \mathrm{SO}_{4}{ }^{2-}+\mathrm{HO}^{*}
\end{aligned}
$$

Step 2. The formation of acrylic acid free radical from vinyl monomer took place as it is susceptible to free radical attack. Simultaneously, free radical may also attack the chitosan at probable positions.

\section{Chain Initiation}

Probabilities (i)<smiles>[X][C+]=CCCC</smiles>

(ii)<smiles>[X]C[CH]C(=O)O</smiles>

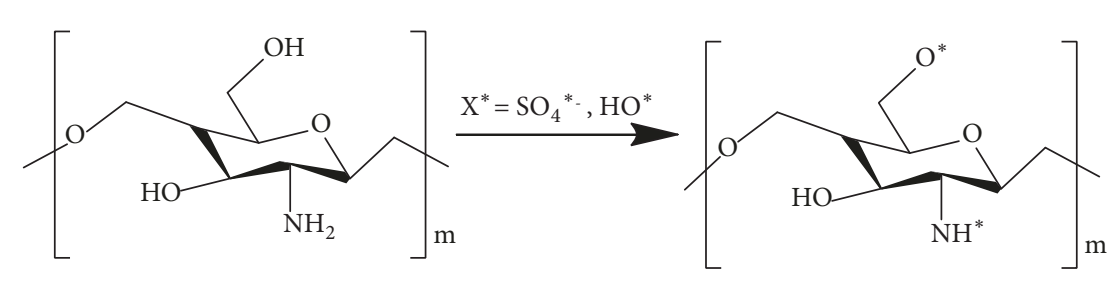

Step 3. The growing chains of the polymer get joined together and incorporate the $\mathrm{TiO}_{2}$ to form the desired nanocomposite. $\mathrm{CA}$ has pendant $-\mathrm{COOH}$ groups, along with terminal chain groups, i.e., primary and secondary $-\mathrm{OH}$ and $-\mathrm{NH}_{2}$, which provides the sites for $\mathrm{TiO}_{2}$ incorporation in the polymeric matrix. This is in accordance with the proposed mechanism for self-assembly between $\mathrm{TiO} 2$ nanoparticles and polymer with $\mathrm{COOH}$ groups [28]. 
Polymerization and Nanocomposite Formation

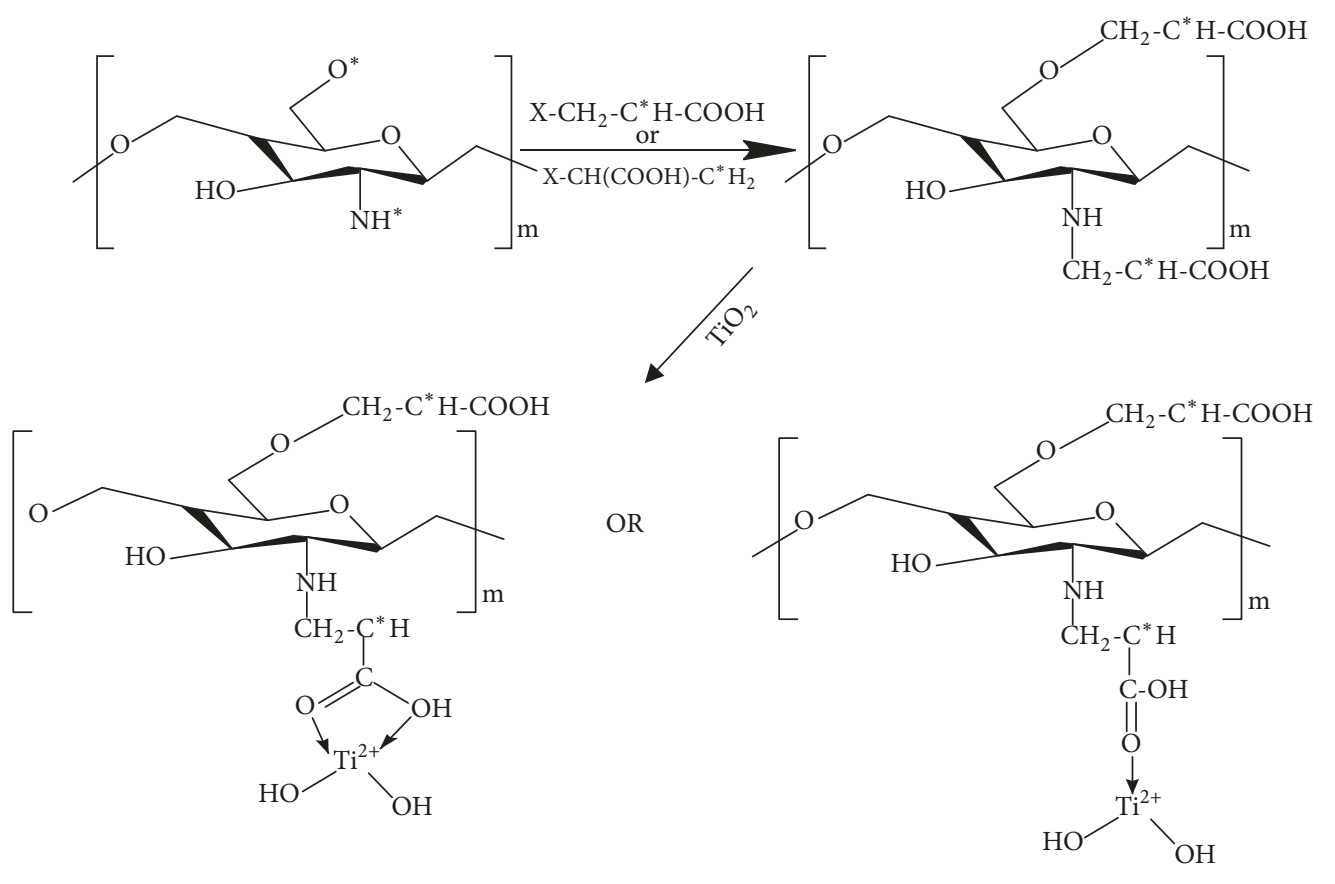

The synthesized CAT was characterized by physiochemical techniques such as X-ray diffraction (XRD), field emission scanning electron microscope (FE-SEM), Fourier Transform Infra-Red spectroscopy (FT-IR), Energy Dispersive X-ray spectroscopy (EDX), and Thermal Gravimetric Analysis (TGA) to obtain the surface morphology, elemental composition, and thermal analysis.

3.1. X-Ray Diffraction Studies. XRD patterns of $\mathrm{TiO}_{2}, \mathrm{CA}$, and CAT are shown in Figures $1(\mathrm{a})-1(\mathrm{c})$, respectively. The typical X-ray diffraction patterns of the synthesized $\mathrm{TiO}_{2}$ show strong diffraction peaks at $25.4^{\circ}, 37.05^{\circ}, 38.6^{\circ}, 48.15^{\circ}$, $53.92^{\circ}$, and $75.28^{\circ}$ and were matched with JCPDS card number 01-073-1764 [17]. X-ray studies support the formation of anatase phase as the main crystal phase for synthesized $\mathrm{TiO}_{2}$. In case of bionanocomposite, CAT sharp peaks at 25.4329, 28.8921, 39.5873, 48.3106, and 51.8367 were observed, which clearly reflects the incorporation of $\mathrm{TiO}_{2}$ into chitosan/acrylic grafted biopolymer.

3.2. FT-IR Analysis. FT-IR spectra of CA biopolymer (Figure 2(a)) show peak at $2924 \mathrm{~cm}^{-1}$ with broad band at 3000 $3500 \mathrm{~cm}^{-1}$ which corresponds to $\mathrm{NH}_{2}$ and $-\mathrm{OH}$ group as compared to the pure chitosan [29]. The $-\mathrm{C}=\mathrm{O}$ bond of carboxylic group of acrylic acid, giving intense peak at 1719 $\mathrm{cm}^{-1}$, confirms the grafting of acrylic acid onto chitosan, and the peak observed at $1263 \mathrm{~cm}^{-1}$ is due to bending vibrations of (C-O) group [29]. In CAT bionanocomposite (Figure 2(b)), there is decrease in intensity peaks at $2968 \mathrm{~cm}^{-1}$ which may be due to loss of double bond character of carbon and presence of $-\mathrm{C}=\mathrm{O}$ group was evident from peak at $1714 \mathrm{~cm}^{-1}$. The additional peaks at $964 \mathrm{~cm}-1$ and $809 \mathrm{~cm}-1$ were due to the presence of Ti-O-C bond and $\mathrm{Ti}-\mathrm{O}$ bond, respectively [30].

3.3. Surface Morphology Analysis. The surface morphology of CA and CAT was investigated by FE-SEM and images are given in Figures 3(a)-3(b), respectively. The morphologies of grafted polymer shows the incorporation of grafted chains of acrylic acid into the backbone. SEM image of CAT indicates the uniform incorporation of $\mathrm{TiO}_{2}$ nanoparticles into the grafted matrix owing to the strong interactions between amphoteric chitosan-acrylic acid and $\mathrm{TiO}_{2}$. Further, the modification of surface morphology is evident from the formation of spherical globules interlinked structure as compared with the cloudy morphology of acrylic acid grafted chitosan due to the transformation of inorganic/polymeric material into composite material with an interlinked structure. The winding of polymer chains around the $\mathrm{TiO}_{2}$ nanoparticles resulted in the growth of globular shaped network nanocomposites. Similar type of observations was reported for chitosan- $\mathrm{ZnO} /$ polyaniline hybrid composites and chitosan (CS) and cellulose acetate (CA) blends containing titanium dioxide ( $\mathrm{TiO} 2)$ nanoparticles [31, 32]. The elemental composition of CA and CAT was confirmed from EDX studies. The presence of $\mathrm{TiO} 2$ in the nanocomposite CAT is evident from EDX graph (Figures 4(a) and 4(b)).

3.4. Thermal Analysis. Thermal analysis curve corresponds to CAT bionanocomposite (Figure 5) showed well differentiation weight loss steps. The first step corresponds to loss of water molecule and any volatile components $(4.09 \%)$ at $101.4^{\circ} \mathrm{C}$. The initial decomposition occurring at temperature 


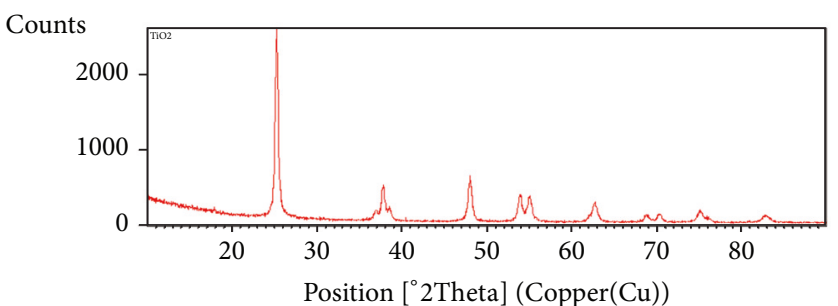

(a)

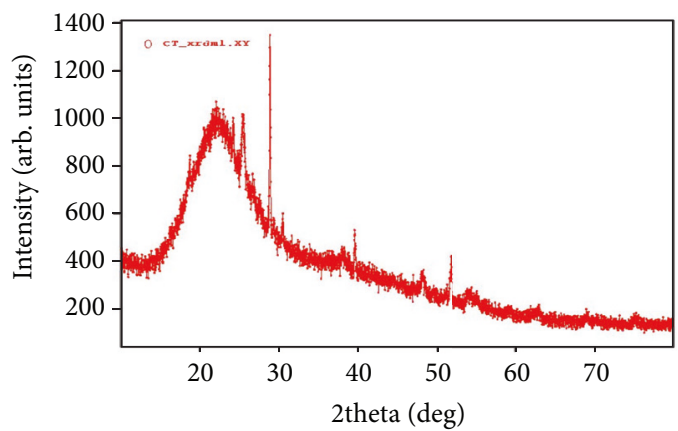

(b)

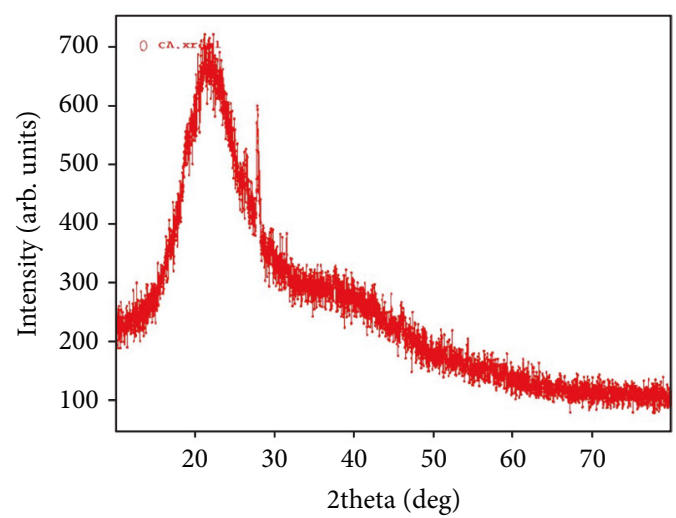

(c)

FIGURE 1: XRD pattern of synthesized $\mathrm{TiO}_{2}(\mathrm{a}), \mathrm{CA}(\mathrm{b})$, and CAT (c).

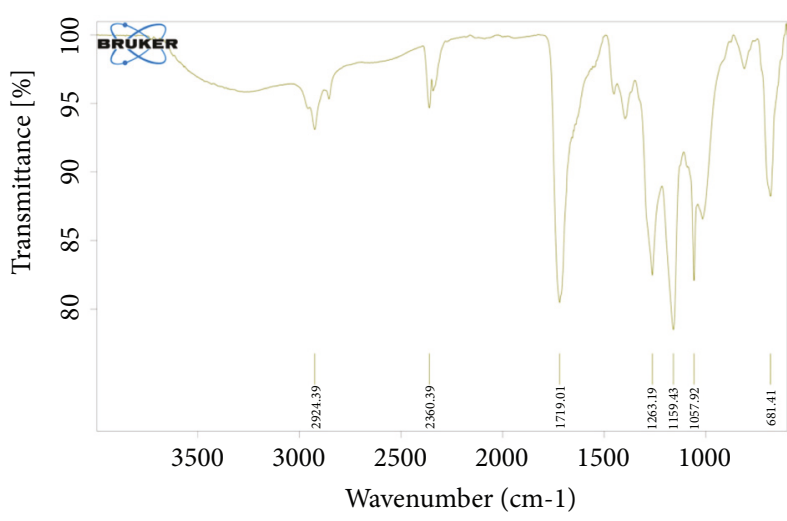

(a)

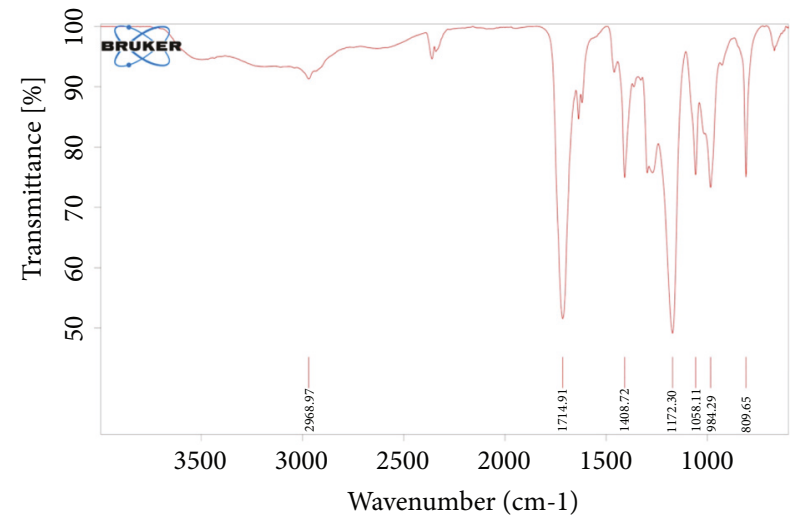

(b)

FIgURE 2: FT-IR spectra of CA biopolymer (a) and CAT bionanocomposite (b).

$252.2^{\circ} \mathrm{C}$ corresponds to $46.20 \%$ weight loss which may be due to breakage/dissociation of the grafted chains from backbone. The other decomposition peak was observed at $354.3^{\circ} \mathrm{C}$ and $505^{\circ}$ due to partial dissociation of chitosan chains and due to the breakage of $\mathrm{TiO}_{2}$ molecules from back bone, and the mass left at $628^{\circ} \mathrm{C}$ corresponds to $11.126 \% \mathrm{TiO}_{2}$ while in case of chitosan-acrylic acid grafted polymer, the final decomposition temperature was less $\left(580^{\circ} \mathrm{C}\right)$ with $4.8 \%$ polymeric mass left [33].

\section{Kinetics of Photocatalytic Degradation of Malachite Green under White Light Using CAT}

Photocatalytic activity of the chitosan-acrylic acid/ $/ \mathrm{TiO}_{2}$ nanocomposite was studied for the photocatalytic degradation of the malachite green dye under the white light. Malachite green shows the absorption peaks at $\lambda_{\max } 617$ $\mathrm{nm}$ in visible region and $\lambda_{\max } 316 \mathrm{~nm}$ in the UV region. 


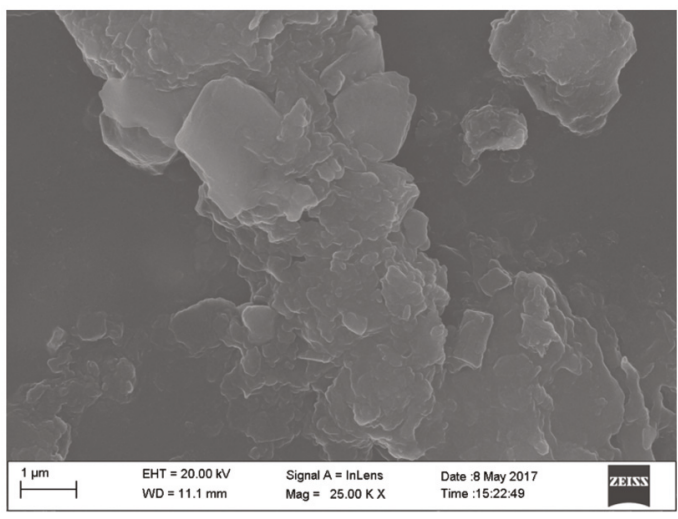

(a)

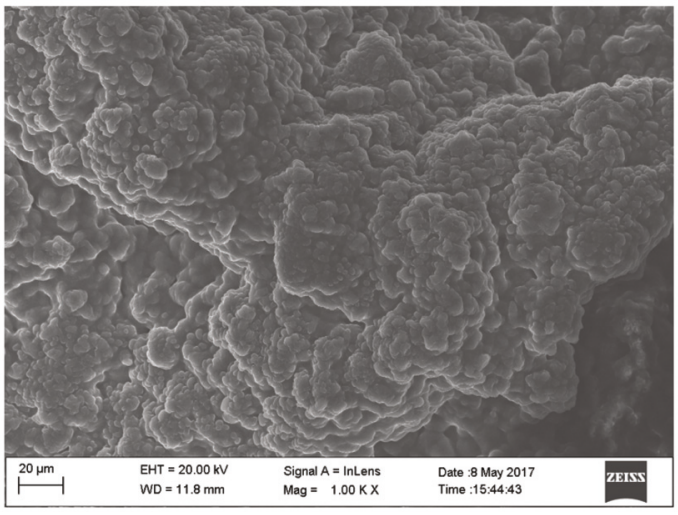

(b)

FIgURE 3: (a-b) SEM of CA and CAT.

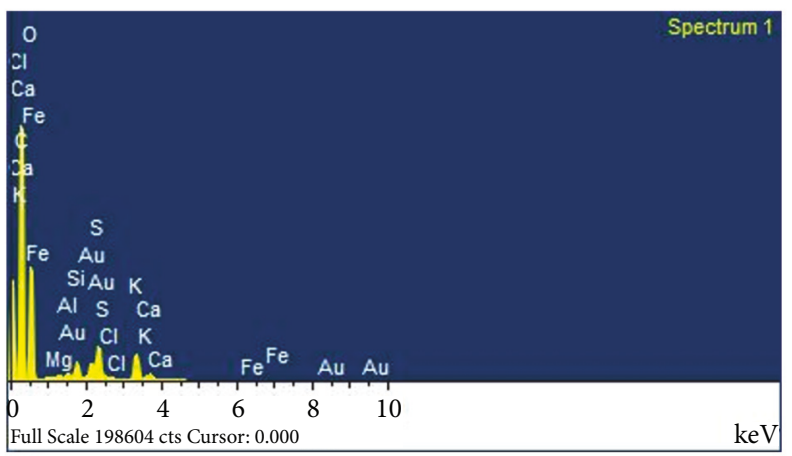

(a)

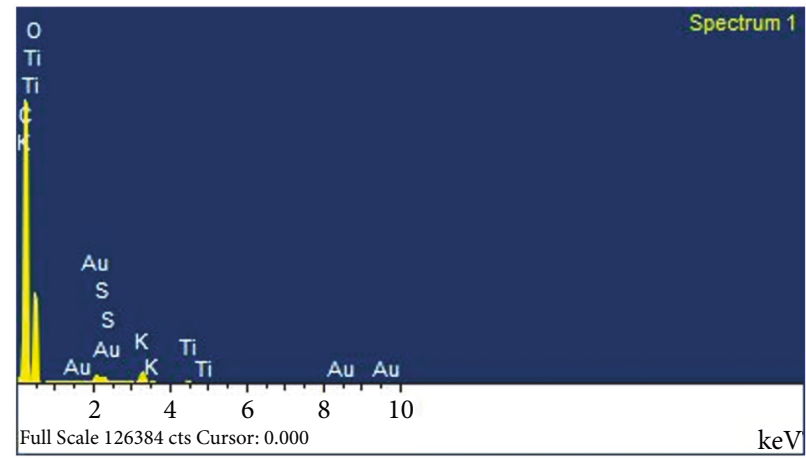

(b)

Figure 4: (a-b) EDX spectra of CA and CAT.

Photocatalytic degradation of malachite green dye has been studied under three different conditions: (i) under white light, (ii) synthesized $\mathrm{TiO} 2$ under white light, (iii) CAT bionanocomposites under white light (Figure 6). The result confirms that the highest degradation of the malachite green dye resulted in the presence of CAT under white light.

The time dependent UV-Vis spectra of malachite green were shown in Figure 7. The decrease in the intensity of both the peaks has been observed with time. Further the degradation of dye during exposure to white light was reflected from the diminishing of the peaks in UV-Vis region. It has been found that $91.94 \%$ of dye has been degraded with CAT.

The $\mathrm{pH}$ of the solution plays an important role in the photocatalytic degradation of dye; therefore experiments were performed with $100 \mathrm{ml}$ (10ppm of MG) by varying $\mathrm{pH}$ of the solution from 2 to 10 keeping the dose of CAT (100mg) constant. It has been observed that maximum degradation was observed at pH 7 (91.94\%) followed by 52.46, 60.7, and $58.2 \%$ at $\mathrm{pH}$ value of 10,4 , and 2 , respectively (Figure 8 ).

Photocatalytic experiments for degradation of malachite green were also performed by changing the initial concentration from 5 to $50 \mathrm{ppm}$. It has been observed that as the concentration of dye increased, the rate of photocatalytic degradation decreases. Figure 9 showed that for 5 ppm, 10 ppm, $25 \mathrm{ppm}$, and $50 \mathrm{ppm}$ solution of malachite green, degradation obtained was 99.5\%, 91.94\%, 58.01, and 38.92\%, respectively. For $10 \mathrm{ppm}$ of the malachite green solution, degradation was $91.94 \%$ in $240 \mathrm{~min}$.

The rate of degradation of the malachite green (10 ppm) is shown in Figure 10. The experimental data was fit into the Langmuir-Hinshelwood equation, $\ln \left(\mathrm{C}_{0} / \mathrm{C}_{\mathrm{t}}\right)=\mathrm{kt}$, where $\mathrm{C}_{0}$ is initial concentration and $C_{t}$ is concentration at time $t$. The rate constant for the degradation of the malachite green was found to be $7.13 \times 10^{-3} \mathrm{~min}^{-1}$.

The plausible explanation for the performance of bionanocomposites as photocatalyst in white light is as follows:

(i) Synthesized bionanocomposite successfully improves the efficiency of the well-known photocatalyst $\mathrm{TiO}_{2}$ for degradation of the commercial dye malachite green by preventing the recombination reaction. It may be attributed to efficient charge separation of the electrons and holes at the interface of polymer/ $\mathrm{TiO}_{2}$ nanocomposites [34].

(ii) Improvement in photocatalytic efficiency observed with $\mathrm{CA} / \mathrm{TiO}_{2}$ nanocomposites may be attributed to polymeric backbone which provides the number of functional groups for adsorption of pollutants in proximity of the catalyst. 
TGA graph of CAT

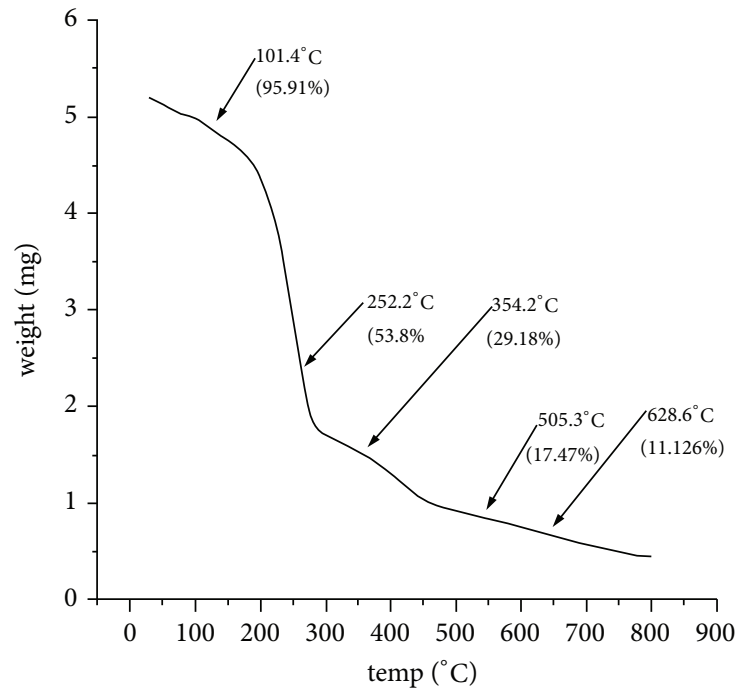

FIGURE 5: Thermal analysis curve of CAT bionanocomposite.

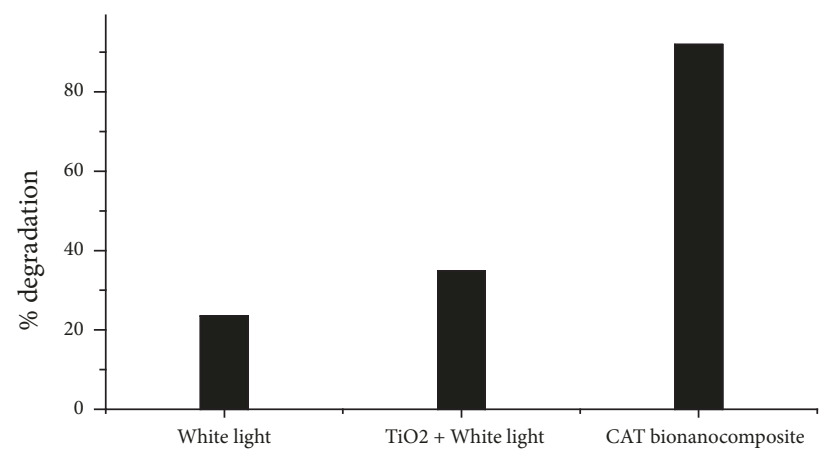

FIGURE 6: Photocatalytic degradation of malachite green dye under three different conditions: (i) under white light, (ii) synthesized $\mathrm{TiO}_{2}$ under white light, (iii) CAT under white light.

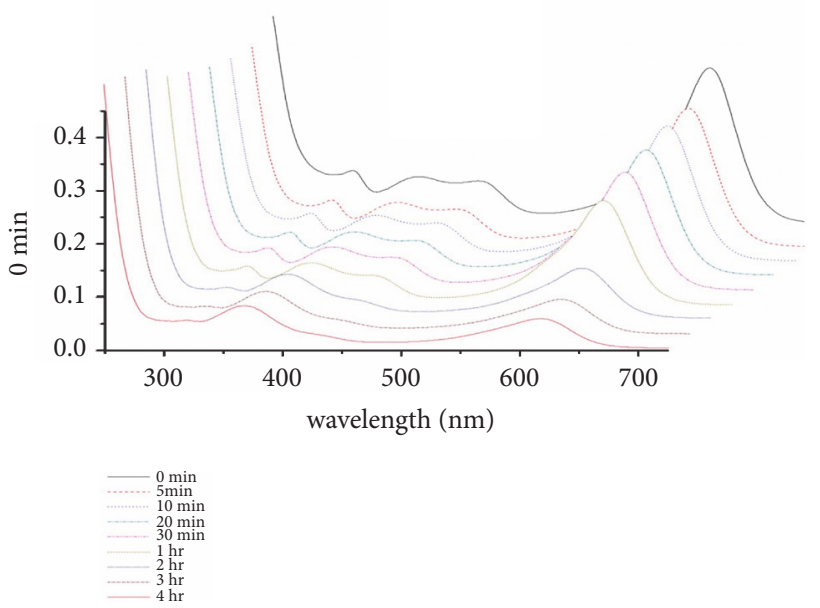

Figure 7: Time dependent UV-Vis spectra of malachite green.

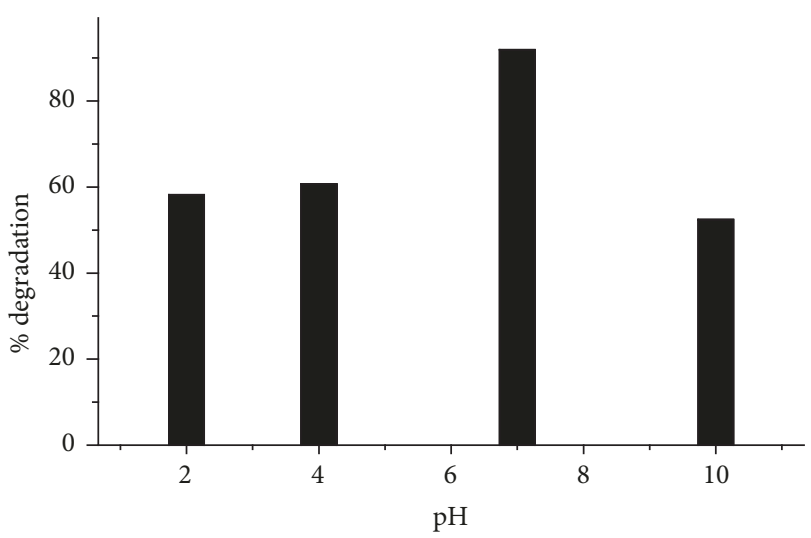

FIGURE 8: Effect of $\mathrm{pH}$ of malachite green solution on photocatalytic degradation.

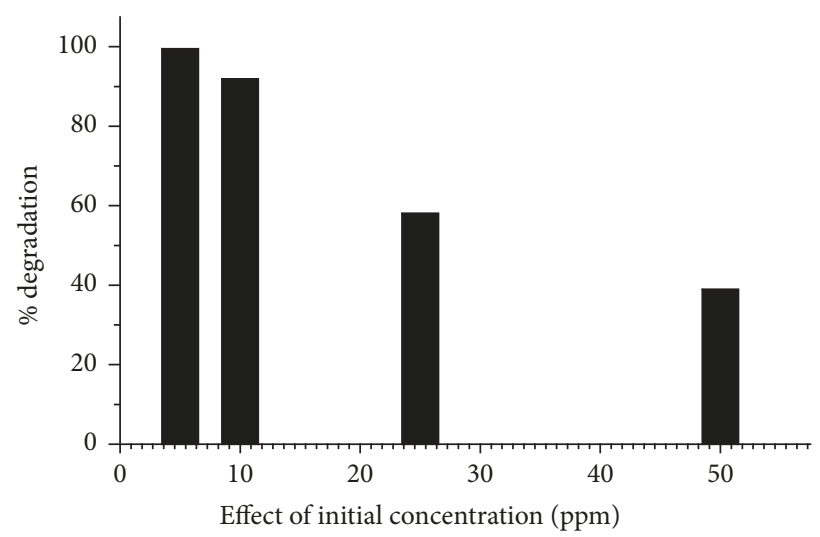

FIGURE 9: Effect of initial concentration of malachite green (ppm) on photocatalytic degradation.

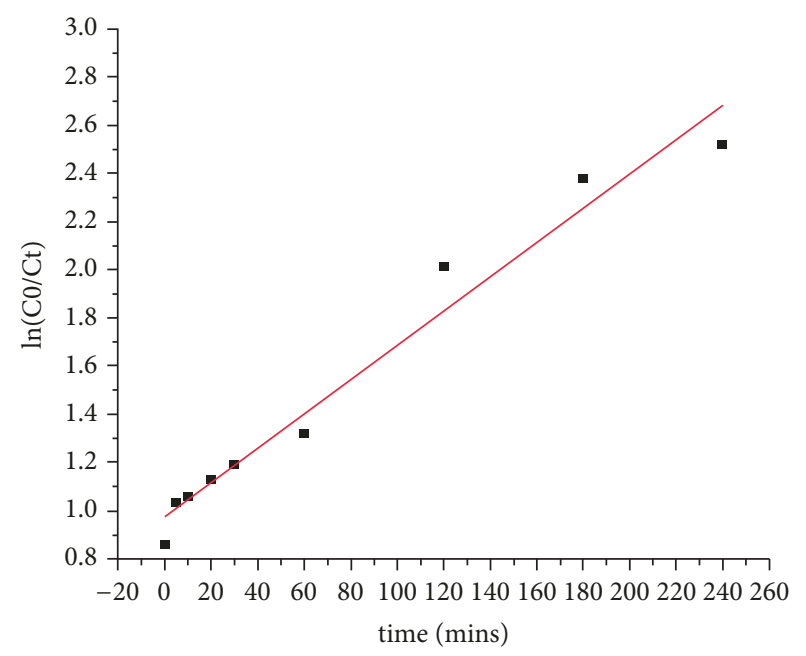

FIGURE 10: Kinetics of the degradation of the malachite green.

(iii) As the usage of $\mathrm{TiO}_{2}$ in suspension mode needs liquid-solid separation, the bionanocomposite solves the problem of the recovery and reusability of photocatalyst.

(iv) The most important observation in the present investigation is the response of photocatalytic degradation by absorption of visible light; otherwise, $\mathrm{TiO}_{2}$ has absorption 
edge is in UV region. This probably can be explained as follows: binding of $\mathrm{TiO}_{2}$ to the amphoteric chitosan resulted in mixing of the metal orbitals with the ligand orbitals or extension of conjugation which allows the movement of electrons in the extended space and leads to the lowering of the excitation energy. This may lead to the response of photocatalyst embedded in nanocomposites in the visible light. Moreover, the presence of $n \& \pi$ system of the CAT provided further movement of the electron, thereby preventing recombination reaction.

\section{Conclusions}

The greener synthesis $\mathrm{CA} / \mathrm{TiO}_{2}$ nanocomposites were synthesized from grafted acrylic acid/chitosan which contains a weak anionic group $(-\mathrm{COOH})$ using ultrasonic waves. The synthesized CA (acrylic acid/chitosan) and CAT $\left(\mathrm{CA} / \mathrm{TiO}_{2}\right)$ were characterized by employing various physiochemical techniques such as FT-IR spectroscopy, XRD, thermal analysis, morphological analysis, and EDX. The photocatalytic efficiency of CAT in white light was investigated for degradation of industrial dye-malachite green. The rate constant of the reaction for degradation of malachite green was found to be $7.13 \times 10^{-3} \mathrm{~min}^{-1}$. The development of novel polymeric nanocomposites offers the potential to introduce new traits in the waste water treatment technology. The response of nanocomposites in the visible light is much desired characteristics for finding an energy and cost-effective solutions for photocatalysis based water purification and treatment.

\section{Data Availability}

The data used to support the findings of this study are available from the corresponding author upon request.

\section{Disclosure}

The abstract was presented in the 4th Edition of International Conference on Polymer Science and Technology.

\section{Conflicts of Interest}

The authors declare that they have no conflicts of interest.

\section{Acknowledgments}

The authors are thankful to the authorities of Sant Longowal Institute of Engineering and Technology, Longowal, for providing financial assistance. They are also pleased to acknowledge the facilities provided by Panjab University, Chandigarh; All India Institutes of Medical Sciences (AIIMS), Delhi; Central University, Bathinda; National Institute of Technology, Jalandhar; and Thapar University, Patiala.

\section{References}

[1] M. W. Luckenbach, P. D. Fur, M. L. Kellogg, and P. V. Veld, "Potential effects of endocrine disrupting compounds on bivalve populations in chesapeake bay: a review of current knowledge and assessment of research needs," in Chesapeake Research Consortium, pp. 10-170, Edgewater, NJ, USA, 2009.

[2] H. D. Mansilla, M. C. Cristina Yeber, J. Freer, J. Rodríguez, and J. Baeza, "Homogeneous and heterogeneous advanced oxidation of a bleaching effluent from the pulp and paper industry," Water Science and Technology, vol. 35, no. 4, pp. 273-278, 1997.

[3] C. M. Browner, J. C. Fox, S. Frace, M. B. Rubin, E. B. Chief, and F. Hund, Development document for final effluent limitations guidelines and standards for the pharmaceutical manufacturing point source category, Engineering and Analysis Division Office Science and Technology, US Environmental Protection Agency, Wash, USA, 1998.

[4] M. Noorjahan, M. Pratap Reddy, V. Durga Kumari, B. Lavédrine, P. Boule, and M. Subrahmanyam, "Photocatalytic degradation of $\mathrm{H}$-acid over a novel $\mathrm{TiO} 2$ thin film fixed bed reactor and in aqueous suspensions," Journal of Photochemistry and Photobiology A: Chemistry, vol. 156, no. 1-3, pp. 179-187, 2003.

[5] I. M. Arabatzis, S. Antonaraki, T. Stergiopoulos et al., "Preparation, characterization and photocatalytic activity of nanocrystalline thin film $\mathrm{TiO}_{2}$ catalysts towards 3,5-dichlorophenol degradation," Journal of Photochemistry and Photobiology A: Chemistry, vol. 149, no. 1-3, pp. 237-245, 2002.

[6] F. Kiriakidou, D. I. Kondarides, and X. E. Verykios, “The effect of operational parameters and $\mathrm{TiO} 2$-doping on the photocatalytic degradation of azo-dyes," Catalysis Today, vol. 54, no. 1, pp. 119-130, 1999.

[7] Y. Hu, H. Tsai, and C. Huang, "Effect of brookite phase on the anatase-rutile transition in titania nanoparticles," Journal of the European Ceramic Society, vol. 23, no. 5, pp. 691-696, 2003.

[8] J. Fisher and T. A. Egerton, Titanium compounds, inorganic, Kirk-Othmer encyclopaedia of chemical technology, Wiley, New York, NY, USA, 2001.

[9] A. Di Paola, E. García-López, S. Ikeda, G. Marc, B. Ohtani, and L. Palmisano, "Photocatalytic degradation of organic compounds in aqueous systems by transition metal doped polycrystalline $\mathrm{TiO}_{2}$," Catalysis Today, vol. 75, no. 1-4, pp. 8793, 2002.

[10] M. R. Hoffmann, S. T. Martin, W. Y. Choi, and D. W. Bahnemann, "Environmental applications of semiconductor photocatalysis," Chemical Reviews, vol. 95, no. 1, pp. 69-96, 1995.

[11] E. Bet-Moushoul, Y. Mansourpanah, K. Farhadi, and M. Tabatabaei, " $\mathrm{TiO}_{2}$ nanocomposite based polymeric membranes: a review on performance improvement for various applications in chemical engineering processes," Chemical Engineering Journal, vol. 283, pp. 29-46, 2016.

[12] R. Asahi, T. Morikawa, T. Ohwaki, K. Aoki, and Y. Taga, "Visible-light photocatalysis in nitrogen-doped titanium oxides," Science, vol. 293, no. 5528, pp. 269-271, 2001.

[13] L. Jianhua, Y. Rong, and L. Songmei, "Preparation and characterization of the $\mathrm{TiO} 2-\mathrm{V} 2 \mathrm{O} 5$ photocatalyst with visible-light activity," Rare Metals, vol. 25, pp. 636-642, 2006.

[14] P. Kaur and D. Sud, "Photocatalytic degradation of quinalphos in aqueous $\mathrm{TiO} 2$ suspension: Reaction pathway and identification of intermediates by GC/MS," Journal of Molecular Catalysis A: Chemical, vol. 365, pp. 32-38, 2012.

[15] F. Peng, L. Cai, L. Huang, H. Yu, and H. Wang, "Preparation of nitrogen-doped titanium dioxide with visible-light photocatalytic activity using a facile hydrothermal method," Journal of Physics and Chemistry of Solids, vol. 69, no. 7, pp. 1657-1664, 2008. 
[16] I. Nakamura, N. Negishi, S. Kutsuna, T. Ihara, S. Sugihara, and K. Takeuchi, "Role of oxygen vacancy in the plasma-treated $\mathrm{TiO}_{2}$ photocatalyst with visible light activity for NO removal," Journal of Molecular Catalysis A: Chemical, vol. 161, no. 1-2, pp. 205-212, 2000.

[17] N. Sharotri and D. Sud, "Greener approach to synthesize visible light responsive nanoporous S-doped $\mathrm{TiO}_{2}$ with enhanced photocatalytic activity," New Journal of Chemistry, vol. 39, no. 3, pp. 2217-2223, 2015.

[18] N. Sharotri and D. Sud, "Studies on visible light induced photocatalysis by synthesized novel $\mathrm{Mn}-\mathrm{S}$ co-doped $\mathrm{TiO} 2$ for remediation of pollutants. Sep puriftechnol," Separation and Purification Technology, vol. 183, pp. 382-391, 2017.

[19] M. De Lima, M. Freire, J. Fonseca, and M. Pereira, "Chitosan membranes modified by contact with poly(acrylic acid)," Carbohydrate Research, vol. 344, no. 13, pp. 1709-1715, 2009.

[20] S. Benamer, M. Mahlous, D. Tahtat et al., "Radiation synthesis of chitosan beads grafted with acrylic acid for metal ions sorption," Radiation Physics and Chemistry, vol. 80, no. 12, pp. 1391-1397, 2011.

[21] Y. Wu, J. Guo, W. Yang, C. Wang, and S. Fu, "Preparation and characterization of chitosan-poly(acrylic acid) polymer magnetic microspheres," Polymer Journal, vol. 47, no. 15, pp. 5287-5294, 2006.

[22] Y.-E. Moon, G. Jung, J. Yun, and H.-I. Kim, "Poly(vinyl alcohol)/poly(acrylic acid)/ $/ \mathrm{TiO}_{2} /$ graphene oxide nanocomposite hydrogels for $\mathrm{pH}$-sensitive photocatalytic degradation of organic pollutants," Materials Science and Engineering: $B$ Advanced Functional Solid-State Materials, vol. 178, no. 17, pp. 1097-1103, 2013.

[23] C. Hou, T. Jiao, R. Xing, Y. Chen, J. Zhou, and L. Zhang, "Preparation of $\mathrm{TiO} 2$ nanoparticles modified electrospun nanocomposite membranes toward efficient dye degradation for wastewater treatment," Journal of the Taiwan Institute of Chemical Engineers, vol. 78, pp. 118-126, 2017.

[24] G. Xiao, H. Su, and T. Tan, "Synthesis of core-shell bioaffinity chitosan- $\mathrm{TiO}_{2}$ composite and its environmental applications," Journal of Hazardous Materials, vol. 283, pp. 888-896, 2015.

[25] A. Pawlak and M. Mucha, "Thermogravimetric and FTIR studies of chitosan blends," Thermochimica Acta, vol. 396, no. 1-2, pp. 153-166, 2003.

[26] R. S. Dassanayake, E. Rajakaruna, and N. Abidi, "Preparation of aerochitin $\mathrm{TiO} 2$ composite for efficient photocatalytic degradation of methylene blue," Journal of Applied Polymer Science, vol. 135, no. 8, p. 45908, 2017.

[27] BS. Saruchi Kaith, R. Jindal, and G. Kapur, "Enzyme-based green approach for the synthesis of gum tragacanth and acrylic acid cross-linked hydrogel: its utilization in controlled fertilizer release and enhancement of water-holding capacity of soil," Iranian Polymer Journal, vol. 22, pp. 561-570, 2013.

[28] M. Luo, W. Tang, J. Zhao, and C. Pu, "Hydrophilic modification of poly(ether sulfone) used $\mathrm{TiO} 2$ nanoparticles by a sol-gel process," Journal of Materials Processing Technology, vol. 172, no. 3, pp. 431-436, 2006.

[29] P. Kannusamy and T. Sivalingam, "Chitosan- $\mathrm{ZnO} /$ polyaniline hybrid composites: polymerization of aniline with chitosanZnO for better thermal and electrical property," Polymer Degradation and Stability, vol. 98, no. 5, pp. 988-996, 2013.

[30] G. Lui, J.-Y. Liao, A. Duan, Z. Zhang, M. Fowler, and A. Yu, "Graphene-wrapped hierarchical $\mathrm{TiO} 2$ nanoflower composites with enhanced photocatalytic performance," Journal of Materials Chemistry A, vol. 1, no. 39, pp. 12255-12262, 2013.
[31] S. H. Kim, S.-Y. Kwak, B.-H. Sohn, and T. H. Park, "Design of $\mathrm{TiO}_{2}$ nanoparticle self-assembled aromatic polyamide thinfilm-composite (TFC) membrane as an approach to solve biofouling problem," Journal of Membrane Science, vol. 211, no. 1, pp. 157-165, 2003.

[32] S. Mafirad, M. R. Mehrnia, P. Zahedi, and S. Hosseini, "Chitosan-based nanocomposite membranes with improved properties: effect of cellulose acetate blending and $\mathrm{TiO}_{2}$ nanoparticles incorporation," Polymer Composites, vol. 39, no. 12, pp. 4452-4466, 2017.

[33] N. Bhullar, K. Kumari, and D. Sud, "Studies on chitosan-based superhydrophilic adsorbent for phasing out Rhodamine $6 \mathrm{G}$ dye and $\mathrm{Cd}^{2+}$ ions from aqueous solutions," Desalination and Water Treatment, vol. 95, pp. 355-364, 2017.

[34] S. Ameen, M. S. Akhtar, Y. S. Kim, and H. S. Shin, "Nanocomposites of poly(1- naphthylamine)/SiO2 and poly(1naphthylamine)/ $/ \mathrm{TiO}_{2}$ : comparative photocatalytic activity evaluation towards methylene blue dye," Applied Catalysis B: Environmental, vol. 103, no. 1-2, pp. 136-142, 2011. 


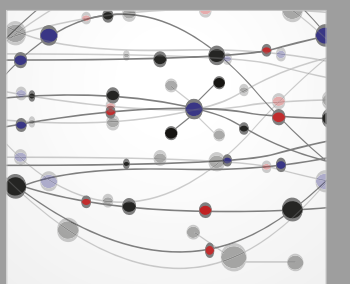

The Scientific World Journal
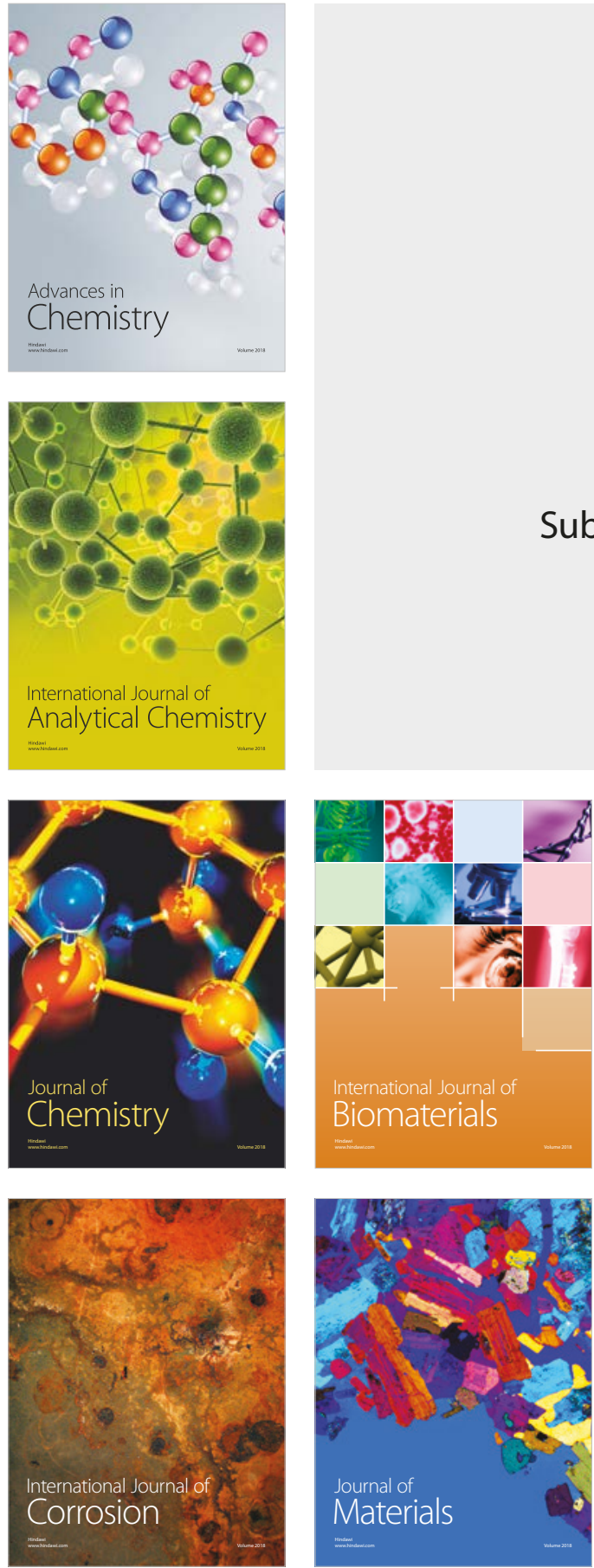

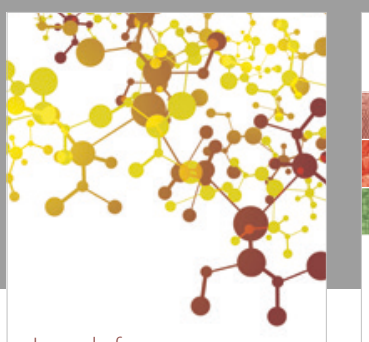

Journal of

Applied Chemistry
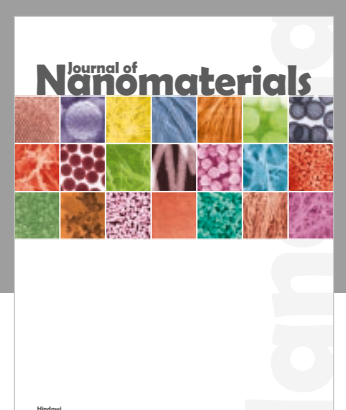

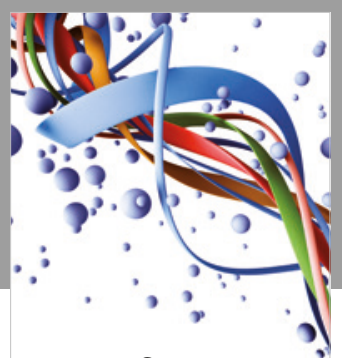

Scientifica

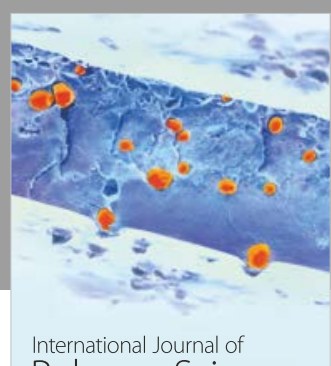

Polymer Science

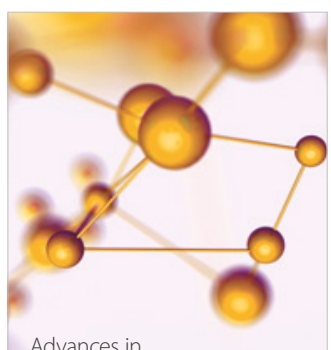

Physical Chemistry
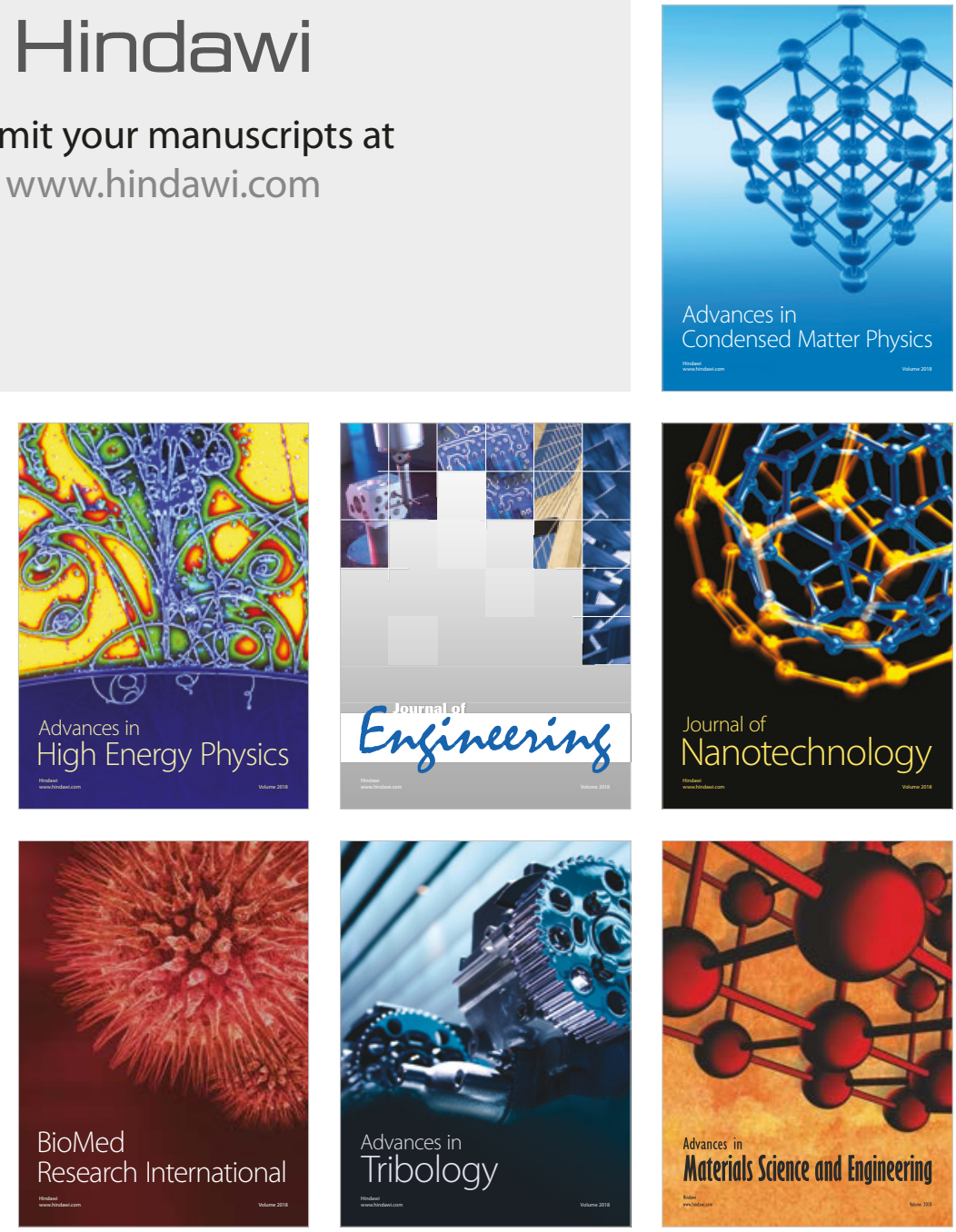